\title{
Externalized phosphatidylinositides on apoptotic cells are eat- me signals recognized by CD14
}

\author{
Ok-Hee Kim ${ }^{1}$, Geun-Hyung Kang ${ }^{1}$, June Hur ${ }^{1}$, Jinwook Lee', YunJae Jung ${ }^{2}$, In-Sun Hong $\mathbb{1}^{3}$, Hookeun Lee ${ }^{4}$, Seung-Yong Seo ${ }^{4}$,

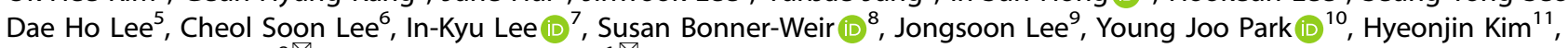 \\ Steven E. Shoelson (1D ${ }^{8 凶}$ and Byung-Chul Oh (1) ${ }^{1 凶}$
}

(c) The Author(s) 2022

Apoptotic cells are rapidly engulfed and removed by phagocytes after displaying cell surface eat-me signals. Among many phospholipids, only phosphatidylserine (PS) is known to act as an eat-me signal on apoptotic cells. Using unbiased proteomics, we identified externalized phosphatidylinositides (PIPs) as apoptotic eat-me signals recognized by CD14 ${ }^{+}$phagocytes. Exofacial PIPs on the surfaces of early and late-apoptotic cells were observed in patches and blebs using anti-PI $(3,4,5) \mathrm{P}_{3}$ antibody, AKT- and PLC $\delta \mathrm{PH}-$ domains, and CD14 protein. Phagocytosis of apoptotic cells was blocked either by masking exofacial PIPs or by CD14 knockout in phagocytes. We further confirmed that exofacial PIP $^{+}$thymocytes increased dramatically after in vivo irradiation and that exofacial $\mathrm{PIP}^{+}$cells represented more significant populations in tissues of $\mathrm{Cd}_{14}^{-1-}$ than WT mice, especially after induction of apoptosis. Our findings reveal exofacial PIPs to be previously unknown cell death signals recognized by CD14 ${ }^{+}$phagocytes.

Cell Death \& Differentiation (2022) 29:1423-1432; https://doi.org/10.1038/s41418-022-00931-2

\section{INTRODUCTION}

Apoptotic cells initiate their own clearance by displaying cell surface eat-me signals which are recognized by tissue phagocytes [1, 2]. The rapid removal of apoptotic cells avoids potential inflammatory responses and the release of cellular contents, which damages tissues and promotes autoimmunity. Many eat-me signals have been identified, including phosphatidylserine (PS), oxidised lipids, intercellular adhesion molecule-3, and calreticulin [3, 4]. Externalized PS is a well-established eat-me signal for the phagocytic clearance of apoptotic cells $[1,2,5-8]$. Over 20 distinct phagocyte proteins of various structural classes are associated with PS-mediated recognition and clearance $[2,9]$. This suggests that regions of the plasma membrane lose phospholipid polarity as cells undergo apoptosis, which is otherwise maintained with high fidelity through energydependent transporters and flippases [10-12].

PS, phosphatidylethanolamine (PE), and phosphatidylinositides (PIPs) are normally restricted to the cytoplasmic leaflet of the plasma membrane, whereas phosphatidylcholine (PC) and sphingomyelin are more prevalent in the outer leaflet. This asymmetric distribution of phospholipids in the inner and outer leaflets of the bilayer influences membrane biophysical properties and plays an essential role in cell signaling and regulation [11, 13]. Perturbations in phospholipid asymmetry are uncommon, with the noted exception of externalized PS serving as an apoptotic cell eat-me signal to trigger cell removal by phagocytes via efferocytosis $[1,2,5,6,9]$. PIPs have small but highly dynamic intracellular concentrations and regulate a wide variety of intracellular processes, including vesicle transport, cytoskeletal reorganization, and signal transduction [1416]. However, neither the existence of externalized PIPs nor their physiological functions have been previously described.

CD14 binds and chaperones bacterial lipopolysaccharide (LPS) to Toll-like receptor-4 (TLR4) at the cell surface [17]. CD14 is also known as a co-receptor for recognition and endocytosis of bacterial LPS along with TLR4 [18] and myeloid differentiation factor 2 (MD-2) $[19,20]$. Apoptotic cells have been shown to accumulate in the tissues of $C d 14^{-/-}$mice [21], suggesting that CD14 may function in the clearance of apoptotic cells as well as bacteria. Previous studies have also shown that CD14 mediates the cellular uptake and metabolism of extracellular PIPs [22], although the potential apoptotic eat-me signals recognized by CD14 remain unknown $[21,23,24]$. These results suggest that CD14 could potentially interact with externalized cellular PIPs as eat-me signals for recognizing apoptotic cells.

Our previous studies suggested that iron-calcium inositol hexakisphosphate $\left(\mathrm{IC}-\mathrm{IP}_{6}\right)$ is the phagocytic target for macrophages in vivo $[25,26]$. Therefore, we performed unbiased $I_{6}$ -

\footnotetext{
'Department of Physiology, Lee Gil Ya Cancer and Diabetes Institute, Gachon University College of Medicine, Incheon 21999, Republic of Korea. ${ }^{2}$ Department of Microbiology, Lee Gil Ya Cancer and Diabetes Institute, Gachon University College of Medicine, Incheon 21999, Republic of Korea. ${ }^{3}$ Department of Molecular Medicine, Lee Gil Ya Cancer and Diabetes Institute, Gachon University College of Medicine, Incheon 21999, Republic of Korea. ${ }^{4}$ College of Pharmacy, Gachon University, Incheon 21936 , Republic of Korea.

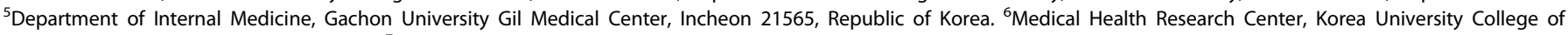
Medicine, Seoul 02841, Republic of Korea. ${ }^{7}$ Department of Biomedical Science, Graduate School of Medicine, Kyungpook National University, Daegu 41404, Republic of Korea. ${ }^{8}$ Joslin Diabetes Center and Department of Medicine, Harvard Medical School, One Joslin Place, Boston, MA 02215, USA. ${ }^{9}$ Soonchunhyang Institute of Medi-bio Science (SIMS),

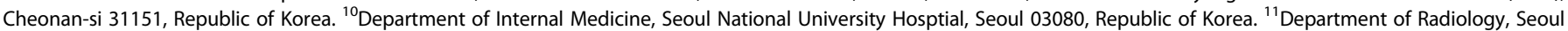
National University College of Medicine, Seoul 03080, Republic of Korea. ${ }^{凶}$ email: steven.shoelson@joslin.harvard.edu; bcoh@gachon.ac.kr Edited by M Piacentini
} 
based affinity proteomics to investigate how macrophages preferentially engulf $\mathrm{IC}-\mathrm{IP}_{6}$. We found that $\mathrm{CD}_{14}{ }^{+}$macrophages specifically bind and take up IC-IP 6 , which mimics the headgroup of PIPs. We hypothesized that $\mathrm{CD} 14^{+}$phagocytes would recognize and engulf apoptotic cells that displayed externalized PIPs on their surfaces in response to apoptotic stimuli. We found that externalized PIPs on the apoptotic cell surface could be an eatme signal recognized by $\mathrm{CD}_{14}{ }^{+}$phagocytes. Collectively, we showed that $\mathrm{PIP}_{3}$ has two opposing signaling roles in determining cell fate; flipped $\mathrm{PIP}_{3}$ is a cell death signal recognized by phagocytes, whereas inward-facing $\mathrm{PIP}_{3}$ elicits survival signals for cell growth [27, 28].

\section{MATERIALS AND METHODS \\ Animal care and use}

WT and $\mathrm{Cd} 14^{-1-} \mathrm{C} 5 \mathrm{BI} / 6$ mice were obtained from the Jackson Laboratory. Male mice were studied under protocols approved by the Animal Ethics Committee of Gachon University, Lee Gil Ya Cancer and Diabetes Institute (LCDI20130062, LCDI20160030, and LCDI20210035).

\section{Detection of externalized PIPs}

Apoptosis was induced using camptothecin $(10 \mu \mathrm{M})$, cycloheximide (200 $\mu \mathrm{M})$, etoposide $(100 \mu \mathrm{M})(\mathrm{ab} 102480$, Abcam), or anti-FAS antibody (305702, $150 \mathrm{ng} / \mathrm{ml}$, BioLegend). Ferroptosis and necroptosis were induced after treatment with selective activators, Erastin (E7781, $1 \mu \mathrm{M}$, Sigma-Aldrich) or L-Buthionine-sulfoximine (BSO) (B2515, $1 \mu \mathrm{M}$, Sigma-Aldrich) for ferroptosis and Emodin (E7881, $5 \mu \mathrm{M}$, Sigma-Aldrich) or Shikonin (S7576, $1 \mu \mathrm{M}$, Sigma-Aldrich) for necroptosis. After fixation, the cells were treated with serum-free protein blocking solution (DAKO) and incubated with anti-PIP IgM antibody (Z-P345, 1:100, Echelon Biosciences), CD14, AKT PHD, AKT$\mathrm{PHD} / \mathrm{eGFP}$, or Annexin V. For immunofluorescence studies, tissue sections $(2.5 \mu \mathrm{m})$ were blocked (DAKO) and incubated with anti-PI $(3,4,5) \mathrm{P}_{3}$ and anticleaved caspase 3 antibodies. After mounting, the sections were imaged with an LSM 700 laser-scanning confocal microscope (Carl Zeiss), and images were analyzed with ZEN 2010 Software (Carl Zeiss).

\section{Flow cytometry}

Jurkat cells treated with camptothecin or FAS antibody and mouse cells were analyzed using LSRII (BD Bioscience) at Core-facility for Cell to In-vivo imaging. $\mathrm{PI}(3,4,5) \mathrm{P}_{3}$ antibody, recombinant $A K T$ PHD, Annexin $\mathrm{V}$, and/or CD14 proteins were used for detection. Annexin V and AKT-PHD were labeled with FITC (53027, Pierce) or Alexa 647 (A20173, Molecular Probes). Cleaved caspase 3 (active) was assessed using Vybrant-FAM, a fluoresceinconjugated caspase 3/7 inhibitor (V35118, Molecular Probes). The data were processed using FlowJo software (Tree Star) [29].

\section{Statistical analysis}

Unless noted otherwise, all data are presented as the mean \pm standard deviation (SD). As described previously [30], group statistical comparisons were performed using unpaired Student's $t$ tests or one-way ANOVA with Tukey's post-hoc multiple comparison test. GraphPad Prism 9.0 (GraphPad Software Inc.) was used for data analysis and graph preparation.

\section{RESULTS}

\section{CD14 binds inositol phosphates and PIPs}

Intravenous administration of technetium-99m-labeled inositol hexakisphosphate $\left({ }^{99 \mathrm{~m}} \mathrm{Tc}-\mathrm{IP}_{6}\right)$ has been used clinically to image the reticuloendothelial system [31]. We developed a related ironcalcium derivative, iron-calcium (IC)- $\mathrm{IP}_{6}$ (Supplementary Fig. 1A), which is taken up by tissue macrophages $[25,26]$. We visualized $\mathrm{IC}_{-} \mathrm{IP}_{6}$ uptake using Prussian Blue (PB) staining and an anti-F4/80 antibody (Fig. 1A). LPS pretreatment of thioglycolate-elicited peritoneal macrophages (TPMs) increased IC-IP 6 uptake (Fig. 1B, $C)$, suggesting that $I C-I P_{6}$ uptake is mediated by an LPS-induced receptor or transporter. To identify potentially responsible proteins, we isolated $\mathrm{IC}^{-\mathrm{IP}_{6}}$-binding proteins from the lysates of LPS-stimulated RAW264.7 macrophages. Proteins separated by SDS-PAGE (Fig. 1D) were cleaved with trypsin and identified using tandem liquid chromatography-mass spectrometry. CD14 fragments were among the most abundantly identified membrane peptides (Supplementary Fig. 1B), and immunoblot analyses confirmed that CD14 was eluted from IC-IP 6 , indicating its selective binding (Fig. 1D). LPS stimulation and hypoxia both induced expression of TPM Cd14 (Supplementary Fig. 1C, D), suggesting that elevated CD14 levels might account for the LPSinduced increase in $\mathrm{IC}^{-\mathrm{IP}_{6}}$ uptake (Fig. $1 \mathrm{~B}, \mathrm{C}$ ). Underscoring the requirement of $\mathrm{CD} 14$ for $I C-\mathrm{IP}_{6}$ uptake, livers from IC-IP -treated $\mathrm{Cd}_{14^{-1-}}$ mice contained 9-fold less iron than those of similarly treated WT mice (Supplementary Fig. 1E).

We hypothesized that a structurally related compound to IC-IP 6 (Supplementary Fig. 1F) is a physiologically relevant in vivo ligand for CD14. We therefore expressed full-length human CD14 in mammalian HEK293T cells and examined its binding properties toward $\mathrm{IP}_{6}$-related PIPs [32]. Protein-lipid overlay experiments showed selective binding of CD14 to PIPs but not to PS, PC, PE, phosphatidylinositol (PI), sphingosine 1-phosphate, lysophosphatidic acid, or lysophosphatidylcholine (Fig. 1E). CD14 bound all phosphorylated PIPs, but exhibited the greatest affinity toward PI $(3,4,5) \mathrm{P}_{3}$, with detectable binding at 6.3 pmol (Fig. 1F). We further analyzed the binding properties of CD14 toward various phospholipids by flow cytometry using custom-made lipid nanoparticles, which allowed lipid headgroups to be exposed for biological interactions. Consistently, flow cytometry demonstrated that $\mathrm{CD} 14$ bound $\mathrm{PI}(4,5) \mathrm{P}_{2}$ and $\mathrm{PI}(3,4,5) \mathrm{P}_{3}$ but not $\mathrm{PC}$ or $\mathrm{PS}$ (Fig. 1G). The mean fluorescence intensity (MFI) value showed that CD14 PIP-binding was highly compatible with specific AKT pleckstrin homology domains (PHDs), which play an essential role in recruiting $A K T$ by binding to plasma membrane $\mathrm{PI}(3,4,5) \mathrm{P}_{3}$ or $\mathrm{PI}$ $(3,4) \mathrm{P}_{2}[33,34]$, using an anti-PI(3,4,5) $\mathrm{P}_{3}$ antibody (Supplementary Fig. 1G).

Using isothermal titration calorimetry (ITC), the gold standard for measuring binding affinity, we determined the affinities of CD14 toward soluble $\mathrm{IP}_{6}\left(\mathrm{~K}_{\mathrm{d}}=6.2 \pm 1.2 \mu \mathrm{M}\right)$ (Fig. $\left.1 \mathrm{H}\right)$ and $\mathrm{PI}(3,4,5)$ $P_{3}$ in liposomes $\left(K_{d}=5.6 \pm 0.6 \mu M\right)$ (Supplementary Fig. $\left.1 H\right)$. Modeling studies based on the CD14 structure [35] predicted anchoring of phosphates at the $1,3,4$, and 5 positions of $\mathrm{IP}_{6}$ and $\mathrm{PI}(3,4,5) \mathrm{P}_{3}$ through salt bridges with side chains of R92, R148, $\mathrm{R} 150$, and R230 (Fig. 1I). This may explain why $\mathrm{PI}(3,4,5) \mathrm{P}_{3}$ binds CD14 with the highest apparent affinity (Fig. 1F), as it is the only PIP with phosphate groups at all four positions. Substitutions of conserved arginine residues to create R92 A, R150A, or R92 A/ $\mathrm{R} 148 \mathrm{~A} / \mathrm{R} 230 \mathrm{~A}$ (R4A) resulted in marked decreases in CD14 binding toward all PIPs (Supplementary Fig. 11). The high-affinity binding of PIPs (normally inwardly facing) to CD14 (normally outwardly facing) suggested that conditions exist where the two meet, i.e., either PIPs face outward or CD14 faces inward.

\section{Exofacial $\mathrm{PI}(3,4,5) \mathrm{P}_{3}$ on apoptotic cells}

Membrane polarity may be perturbed during apoptosis [11, 13], when normally inwardly facing PS is externalized to become an eat-me signal for macrophages [1, 2, 9, 36]. Given that CD14 may recognize apoptotic cells [21, 23, 24] but not PS [37], we asked whether PIPs were exposed outwardly during apoptosis. Under basal conditions, $\mathrm{PI}(3,4,5) \mathrm{P}_{3}$-antibody binding to both Chinese hamster ovary $(\mathrm{CHO})$ and HeLa cells was negative, but was readily detected after initiation of apoptosis through treatment with an anti-FAS antibody, an inhibitor of protein translation (cycloheximide), or a topoisomerase (camptothecin) (Fig. 2A and Supplementary Fig. 2A). We further tested PIP membrane polarity using the high inherent specificities of AKT and PLC $\delta$ PHDs toward PI $(3,4,5) \mathrm{P}_{3}$ and either $\mathrm{PI}(3,4) \mathrm{P}_{2}$ or $\mathrm{PI}(4,5) \mathrm{P}_{2}$, respectively $[33,34,38]$. Neither PLCS nor AKT PHDs recognized cultured $\mathrm{CHO}$ cells until apoptosis had been initiated with an anti-FAS antibody, cycloheximide, or camptothecin (Fig. 2A and Supplementary Fig. 2B). The fluorescence intensity of externalized PIPs detected by anti-PIP3 antibody, PLC $\mathrm{PHD}$, and AKT PHD, was almost 10 to 50 -fold 

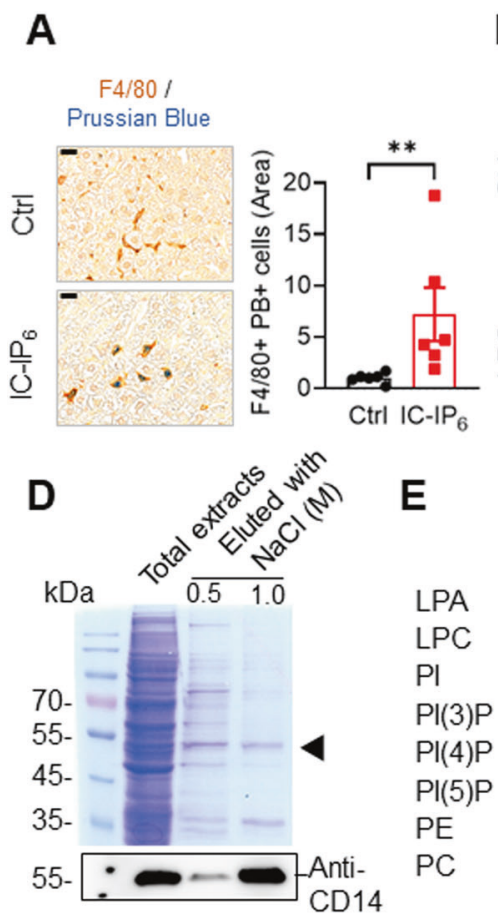

$\mathbf{E}$
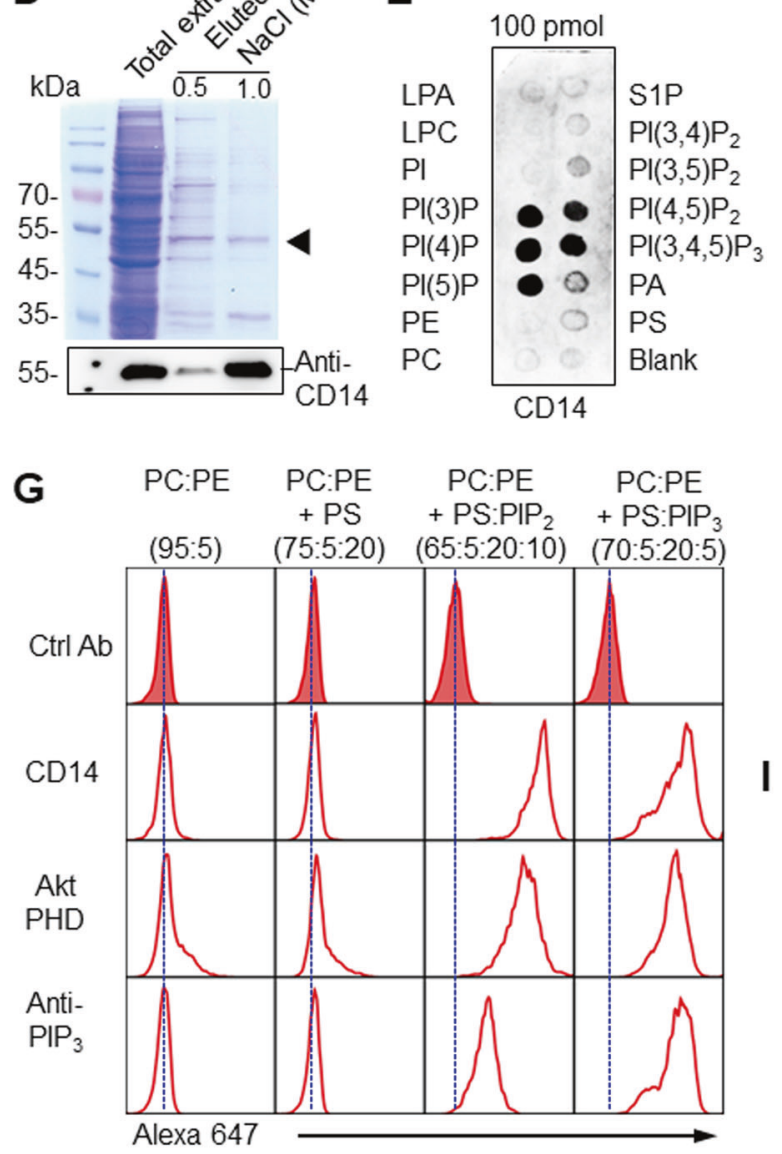

C

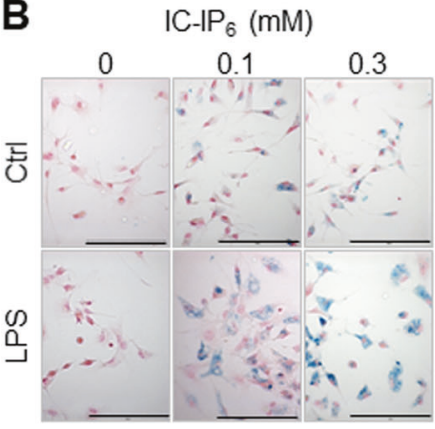

$\mathbf{F}$

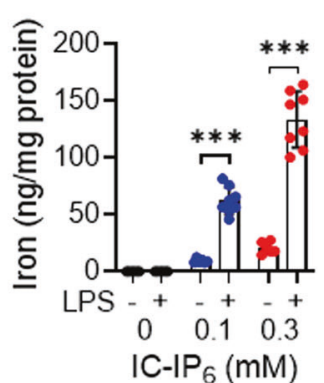

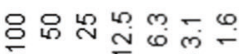

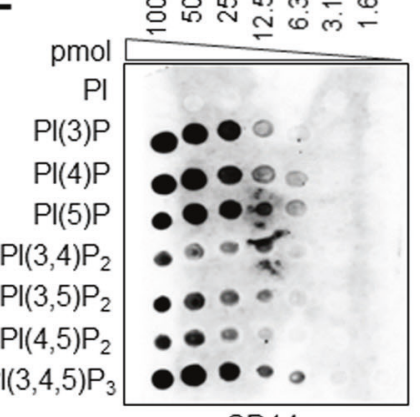

CD14
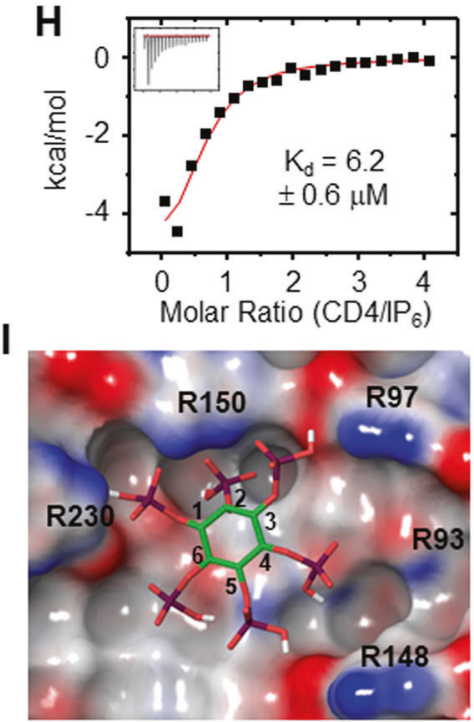

Fig. 1 The role of $\mathrm{CD}_{14}^{+}$macrophages in IC-IP 6 uptake and PIP recognition. Representative liver sections (left) and quantitative data (right) from mice treated with or without intravenous IC-IP 6 ( $n=6$ per group). The liver sections were stained with Prussian blue (PB) for iron and anti-F4/80 antibodies for macrophages/Kupffer cells (scale bars, $20 \mu \mathrm{m}$ ). F4/80+ PB + cells were quantified using ImageJ software. B, C LPS induction of IC-IP 6 uptake by TPMs, determined by PB-stained cells (scale bars, $20 \mu \mathrm{m})(\mathbf{B})$, or (C) by iron staining with 2,4,6-tri-(2-pyridyl)-5triazine (TPTZ) in cell lysates $(n=8)$. Each point represents the mean of three experimental replicates for each IC-IP ${ }_{6}$ concentration. $\mathbf{D}$ Proteins isolated from RAW264.7 cell lysates by IC-IP 6 precipitation were eluted with $\mathrm{NaCl}$, separated by SDS-PAGE, and visualized using Coomassie Brilliant Blue (black arrowhead =CD14). CD14 identity was confirmed by western blotting. E, F CD14 binding to immobilized phospholipids (100 pmol each) (E), and varying concentrations of phosphatidylinositol phosphates (PIP strips or PIP arrays, Echelon Biosciences) (F). G Representative flow cytometry analyses of the binding of CD14, AKT PHD, or anti-PIP ${ }_{3}$ antibody to the indicated phospholipids. Silica particles loaded with specific combinations of phospholipids (Echelon Bioscience) were treated with anti-PI(3,4,5) $\mathrm{P}_{3}$ antibody or His-tagged AKT PHD, or CD14 protein. Samples with His-tagged proteins were treated with primary anti-His antibody, and all were visualized using an Alexa-647-labeled secondary antibody. The blue dotted lines indicate the peaks of the isotype controls. $\mathbf{H}$ ITC results for IP 6 titration into $30 \mu \mathrm{M}$ CD14; the $\mathrm{K}_{d}$ value was determined by curve fitting the raw data $\left(n=2\right.$; MicroCal). I Modeled $\mathrm{PI}(3,4,5) \mathrm{P}_{3}-\mathrm{CD} 14$ structure, generated with AutoDock PyRx and coordinates for $\mathrm{IP}_{6}$ (1ZY7) [50] and CD14 (1WWL) [35]; red (acidic) and blue (basic) are according to the electrostatic potential. $\mathrm{IP}_{6}$ potentially interacts with $\mathrm{CD} 14$ residues $\mathrm{R} 92, \mathrm{R} 97, \mathrm{R} 150$, and R230. All comparisons were performed by one-way ANOVA with Tukey's post-hoc multiple comparison test (Fig. 1C) or unpaired student $t$ test (Fig. 1A). All data are presented as mean \pm standard deviation (SD) for each group. ${ }^{*} p<0.05,{ }^{* *} p<0.01,{ }^{* *} p<0.001$ compared to controls. See also Supplementary Fig. 1. 
A

울
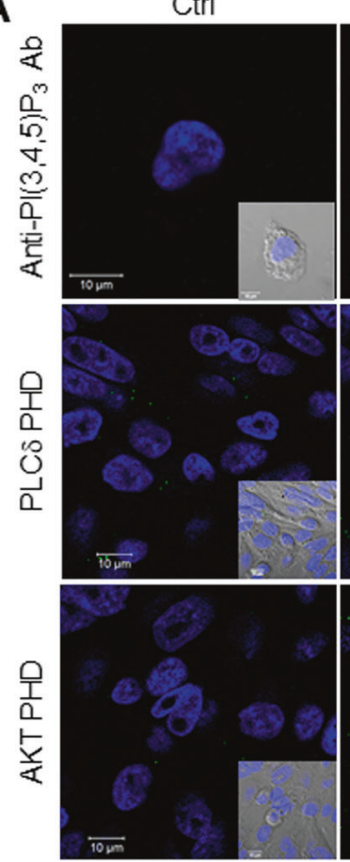

B

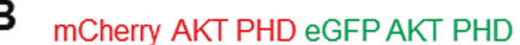

Anti-FAS
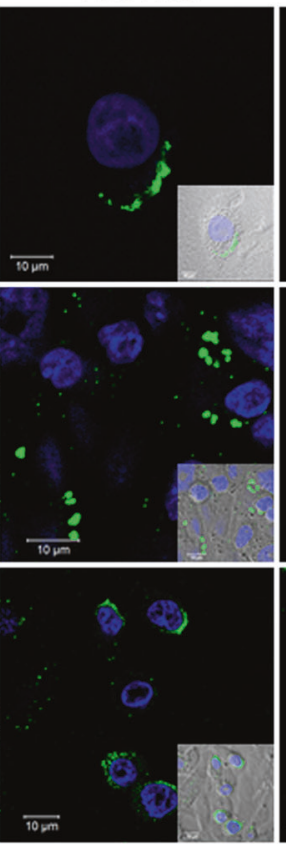

Camptothecin

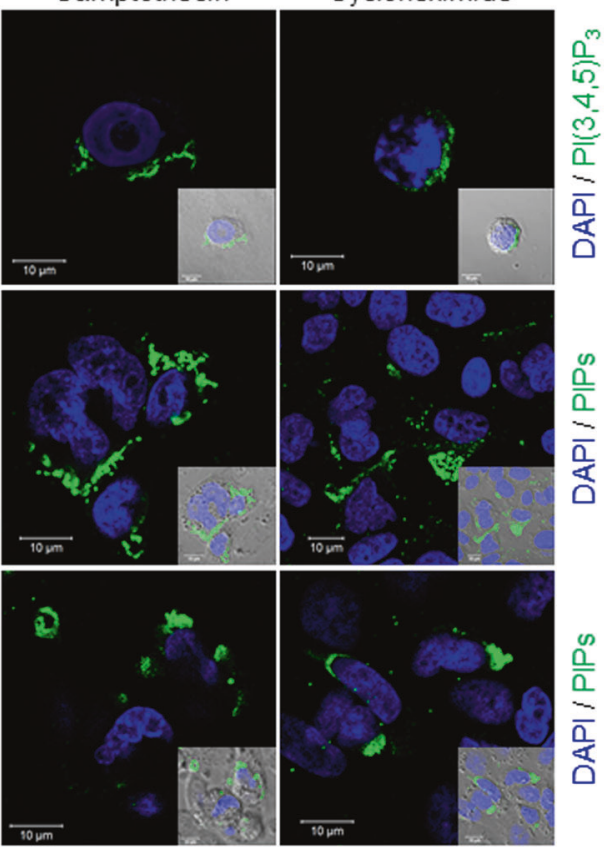

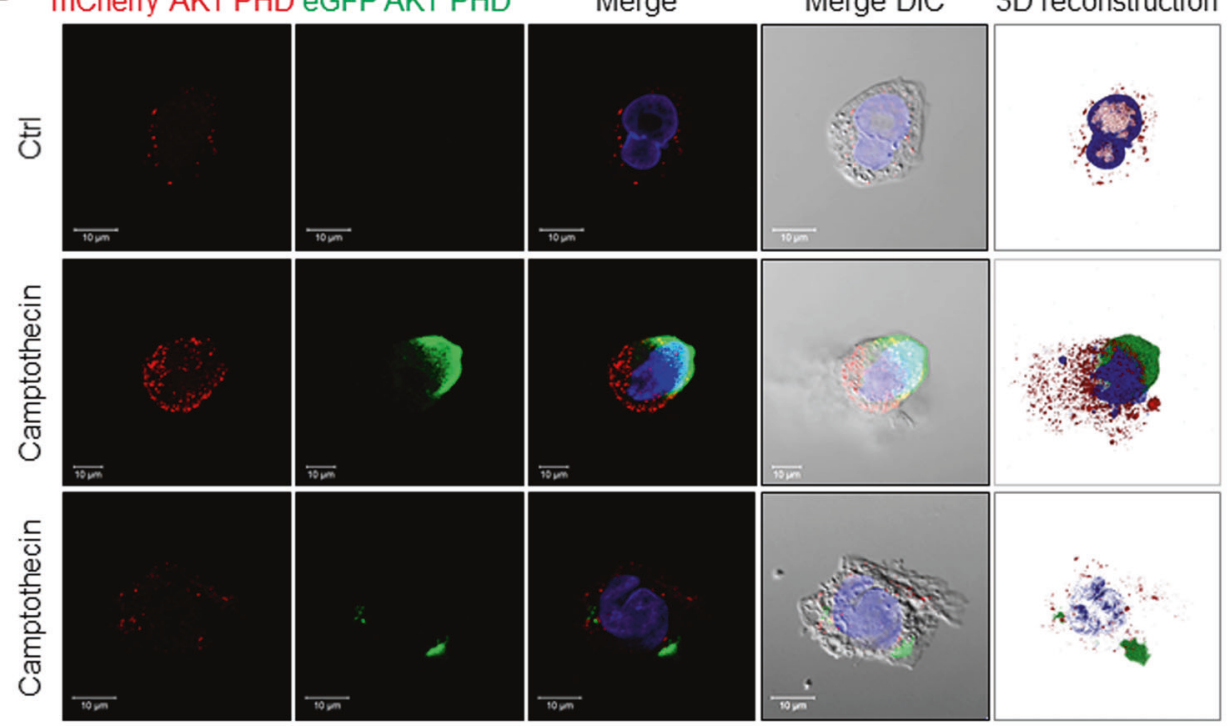

Fig. 2 Visualizing externalized PIPs on apoptotic cells. A Representative images of externalized PIPs on apoptotic HeLa cells. HeLa cell apoptosis was induced by $16 \mathrm{~h}$ treatment with either an anti-FAS antibody ( $100 \mathrm{ng} / \mathrm{ml})$, camptothecin $(10 \mu \mathrm{M})$ or cycloheximide $(100 \mu \mathrm{M})$. Cells were stained using an anti-PI(3,4,5) $\mathrm{P}_{3}$ antibody, recombinant MYC-tagged PLC $\delta$ PHD, or AKT-PHD protein. All were visualized using an FITClabeled secondary antibody and DAPI (scale bars, $10 \mu \mathrm{m}$ ). Inserts use differential interference contrast microscopy. B Representative images of externalized $\mathrm{PI}(3,4) \mathrm{P}_{2}$ and $\mathrm{PI}(3,4,5) \mathrm{P}_{3}$ detection using a recombinant eGFP/AKT PHD fusion protein on CHO cells expressing mCherry/AKT PHD fusion protein. Apoptosis was induced in $\mathrm{CHO}$ cells that stably expressed the mCherry/AKT PHD fusion protein to visualize intracellular PI(3,4) $\mathrm{P}_{2}$ and $\mathrm{PI}(3,4,5) \mathrm{P}_{3}$, while externalized PIPs were visualized using recombinant eGFP/AKT PHD fusion protein (scale bars, $\left.10 \mu \mathrm{m}\right)$. Threedimensional reconstructed images were made using Zeiss Zen SP2 software. Camptothecin-treated cells typically displayed either a large bleb or small patches of eGFP-positive staining; examples of both are shown. Supplementary Movie 1 provides a time-lapse video. See also Supplementary Figs. 2-4.

higher than the PBS control (Supplementary Fig. 2C). These results parallel those obtained with the anti-PI(3,4,5) $\mathrm{P}_{3}$ antibody. Additional studies using an anti-PI $(4,5) \mathrm{P}_{2}$ antibody confirmed its externalization by apoptotic cells, indicating that in addition to PS, several plasma membrane PIPs flip outward during apoptosis to become accessible on the cell surface (Supplementary Fig. 2D).

To further assess PIP membrane polarity and to control for the recognition of intracellular PIPs by extracellular reagents, which may penetrate the leaky plasma membranes of apoptotic cells, we stably expressed the AKT PHD/mCherry fusion protein in $\mathrm{CHO}$ cells that already stably expressed an insulin receptor (CHO/IR) [39].

Upon insulin stimulation, basal punctate staining with the AKTPHD/mCherry fusion protein transitioned to the inner plasma membrane (Supplementary Fig. 3A), consistent with the generation of additional $\mathrm{PI}(3,4,5) \mathrm{P}_{3}$ via insulin-activated $\mathrm{PI}$ 3-kinase $[15,16,34]$. The exogenous AKT PHD/eGFP fusion protein was not visualized basally or after insulin stimulation (Fig. 2B). By contrast, basal intracellular $\mathrm{PI}(3,4,5) \mathrm{P}_{3}$ staining with the intracellular $\mathrm{AKT}$ 
$\mathrm{PHD} / \mathrm{mCherry}$ fusion protein was unchanged by camptothecin, whereas the extracellular AKT PHD/eGFP fusion protein recognized externalized $\mathrm{PI}(3,4,5) \mathrm{P}_{3}$ and showed distinct focal patches on camptothecin-treated apoptotic cell surfaces in the form of either individual large blebs or multiple smaller patches (Fig. 2B, Supplementary Fig. 3B, C, and Supplementary Movie 1). These methods can clearly distinguish inwardly facing from outwardly facing PIPs, and showed that outwardly facing $\mathrm{PI}(3,4,5) \mathrm{P}_{3}$ has a distinct distribution after the induction of apoptosis. In addition to apoptosis, we found that cells undergoing ferroptosis or necroptosis had externalized $\mathrm{PI}(3,4,5) \mathrm{P}_{3}$ on their cell surfaces after treatment with selective activators, Erastin or L-Buthioninesulfoximine (BSO) for ferroptosis $[40,41]$ and Emodin or Shikonin for necroptosis $[42,43]$ (Supplementary Fig. 4A-D). These results suggest that exofacial $\mathrm{PI}(3,4,5) \mathrm{P}_{3}$ is a common cell death marker and not a specific event in apoptosis.

\section{CD14 recognizes exofacial PIPs as eat-me signals}

Recombinant CD14 also bound to the surfaces of HeLa and CHO cells after induction of apoptosis, consistent with CD14 recognition of externalized PIPs (Fig. 3A and Supplementary Fig. 5A, B). By contrast, R4A CD14 did not bind PIPs either in biochemical assays or on apoptotic cells (Fig. 3A). Furthermore, the fluorescence intensity of externalized PIPs by WT CD14 and R4A CD14 mutant protein was almost 30-fold higher than those of the PBS control (Supplementary Fig. 5C). To further assess externalized PIP dependence for macrophage phagocytosis, we performed an in vitro phagocytosis assay using pHrodo-labeled apoptotic Jurkat cells [12]. LPSstimulated TPMs rarely phagocytize healthy Jurkat cells, but treatment with camptothecin caused 10- to 20-fold increases in the phagocytosis of pHrodo-labeled Jurkat cells (Fig. 3B). The Jurkatcell engulfment was inhibited in a dose-dependent manner following pre-incubation with a PIP-specific antibody (anti-PI( $3,4,5)$ $\mathrm{P}_{3}$ ), AKT PHD, CD14, or Annexin V (Fig. 3C). Annexin V, an established and widely used reagent for identifying apoptotic cells, binds to externalized PS [5, 36, 44, 45]. Furthermore, engulfment of apoptotic HeLa or CHO cells by phorbol myristate acetate (PMA)/LPSstimulated human THP1 cells (Supplementary Fig. 6A-D) and engulfment of apoptotic thymocytes by murine RAW264.7 macrophages (Supplementary Fig. 6E, F) were also inhibited following preincubation with AKT PHD, CD14, or annexin V. The results show that the masking PIPs or PS on the apoptotic cell surface inhibits phagocytosis by macrophages from the same species as well as different species. By contrast, TPM phagocytosis of labeled bacteria (Escherichia coli) or synthetic beads was not inhibited after incubation with AKT PHD, Annexin V, or CD14 (Supplementary Fig. 7a), suggesting that PS- or PIP-mediated recognition and engulfment were selective for apoptotic cells and are not involved in either bacterial or latex-bead phagocytosis.

The potential role of CD14 in cellular phagocytosis was further assessed using TPMs isolated from $\mathrm{Cd} 14^{-1-}$ mice. Cd14 ${ }^{-1-}$ TPMs engulfed fewer pHrodo-labeled apoptotic Jurkat cells than WT TPMs (Fig. 3D), despite upregulation of CD36 and other putative eat-me receptors on $\mathrm{Cd} 14^{-/-}$TPMs [1, 3] (Supplementary Fig. 7B). To confirm the biological significance of these in vitro results, we performed in vivo phagocytosis assays by injecting pHrodo-labeled apoptotic thymocytes $\left(8 \times 10^{6}\right.$ cells per mouse) from irradiated C57BL/6 J mice into the peritoneal cavity of either WT or $\mathrm{Cd} 14^{-/-}$ mice. Consistent with in vitro phagocytosis results, in vivo engulfment of pHrodo-labeled apoptotic thymocytes in $\mathrm{Cd}_{14^{-1-}}$ peritoneal macrophages was dramatically less than in WT peritoneal macrophages (Fig. 3E), indicating that loss of CD14 lead to impaired apoptotic thymocyte clearance by phagocytes. To further establish that CD14 recognizes externalized $\mathrm{PIP}_{3}$, we incubated $\mathrm{WT}$ and Cd14 ${ }^{-/-}$TPMs with synthetic Bodipy-labeled $\mathrm{PI}(3,4,5) \mathrm{P}_{3}$ ( $\mathrm{PIP}_{3}$-Bodipy) (Supplementary Fig. 7C). Confocal immunofluorescence microscopy and flow cytometry showed that the engulfment of $\mathrm{PIP}_{3}$-Bodipy was markedly decreased in $C d 14^{-1-}$ TPMs relative to WT TPMs (Fig. 3E,
F). These findings indicate that externalized PIPs serve as eat-me signals for apoptotic cells, CD14 is a phagocyte eat-me signal receptor for externalized PIPs, and externalized PIPs on apoptotic cells and CD14 receptor on macrophages are sufficient for the recognition and engulfment of apoptotic cells.

\section{Kinetics of exofacial PIPs}

We further used flow cytometry and the nucleic acid-binding dye TO-PRO-3 (TP-3) to assess the kinetics and specificity of these interactions and to distinguish early apoptotic from late-apoptotic and necrotic cells [46]. $\mathrm{TP}_{-} 3^{+} \mathrm{PI}^{-}(\mathrm{R} 1)$ and $\mathrm{TP}-3^{+} \mathrm{PI}^{+}$(R2) staining can be used to distinguish between early and late apoptosis, and both are distinct from $\mathrm{TP}^{-} 3^{-} \mathrm{PI}^{+}$(R3) necrosis. Early apoptotic R1 cells showed nearly identical signals for Annexin V, AKT PHD, CD14, and anti-PIP 3 antibody (Fig. 4A, B). Similarly, late-apoptotic R2 cells also showed similar results for Annexin V, AKT PHD, CD14, and anti-PIP 3 antibody, regardless of camptothecin treatment time (Fig. 4A, B). We investigated this result further using a doublestaining approach. The majority of cells labeled with mixtures of AKT-PHD and CD14 were doubly positive (Fig. 4C), consistent with both reagents recognizing externalized PIP signals on apoptotic cells. Similarly, most cells were doubly positive when stained with any pair of Annexin V, AKT PHD, and CD14 (Fig. 4D, E). Confocal immunofluorescence microscopy confirmed that both Annexin $\mathrm{V}$ and AKT PHD bound to apoptotic cells with similar patchy distributions (Fig. 4F, Supplementary Fig. 8A, B, and Supplementary Movie 2). Given the similar externalization kinetics and cell surface distributions of PS and PIPs, both may serve as eat-me signals for the clearance of apoptotic cells.

\section{In vivo exposure of PIP eat-me signals}

To determine whether PIP externalization similarly characterizes apoptotic cells in vivo, we irradiated $\mathrm{C} 57 \mathrm{BI} / 6 \mathrm{~J}$ mice to broadly induce apoptosis in susceptible tissues. Propidium iodide and a fluorescent probe for cleaved, activated caspase 3 (Casp ${ }^{+}$; FAMFLICA, Molecular Probes) were used to relate PIP externalization to the kinetics of apoptosis. Thymocyte apoptosis was readily apparent after irradiation, as numbers of early apoptotic R1 thymocytes and late-apoptotic R2 thymocytes continually increased over time after irradiation (Fig. 5A, B). Consistent with the in vitro results, $74-94 \%$ of early apoptotic R1 thymocytes were AKT $\mathrm{PHD}^{+}, \mathrm{CD}_{14}^{+}$, or Annexin $\mathrm{V}^{+}$, whereas $94-100 \%$ of lateapoptotic R2 thymocytes were AKT $\mathrm{PHD}^{+}, \mathrm{CD} 14^{+}$, or Annexin $\mathrm{V}^{+}$. These findings indicate that cells entering apoptosis often became Casp $^{+}$prior to displaying exofacial PS or PIPs, whereas nearly all late-apoptotic R2 thymocytes displayed externalized PS and PIPs (Fig. 5C). R3 thymocytes may be necrotic rather than apoptotic [5], but they too externalize PS and PIPs. However, the MFI values were markedly lower in R3 compared to R2 thymocytes (Fig. 5D), suggesting that externalized PS and PIP abundance were substantially lower on R3 than R2 thymocytes. Similar to PS exposure, these findings suggest that neither PS nor PIPs externalize early, but instead, both may serve as a marker of mid-to-late apoptosis in vivo and in vitro.

The rapidly dividing cells in intestinal crypts are highly radiation-sensitive. In WT mice, the numbers of Casp ${ }^{+}$apoptotic cells assessed through immunohistochemistry (IHC) in the jejunum increased by 10 - and 20 -fold $4 \mathrm{~h}$ and $16 \mathrm{~h}$ post-irradiation, respectively (Supplementary Fig. 9A, B). We also analyzed Cd14 ${ }^{-1-}$ mice under similar conditions. Prior to irradiation, the number of Casp $^{+}$apoptotic cells was 5 -fold more significant in $\mathrm{Cd} 14^{-1-}$ mice than in WT mice, consistent with CD14 playing a role in the recognition of apoptotic cells $[21,23,24]$. As in WT mice, Casp ${ }^{+}$ cells in $\mathrm{Cd} 14^{-/-}$mice increased after irradiation by 5.6- and 6.6fold at $4 \mathrm{~h}$ and $16 \mathrm{~h}$, respectively. Because the baseline number of apoptotic cells was higher in $\mathrm{Cd} 14^{-1-}$ mice, the fold-change after irradiation was smaller for $\mathrm{Cd}_{14^{-/-}}$mice than for WT mice, but the absolute number of apoptotic cells was always higher in $C d 14^{-/-}$ 
A

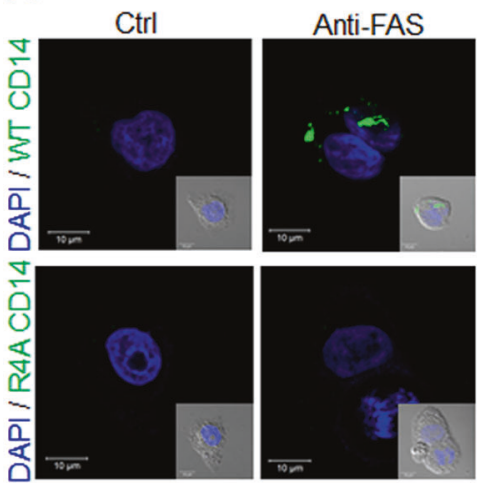

C

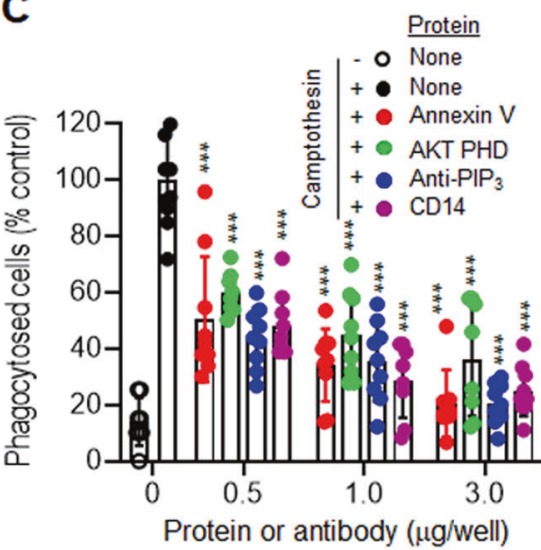

B
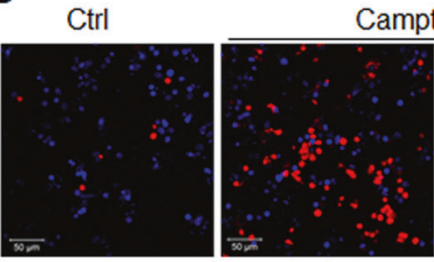

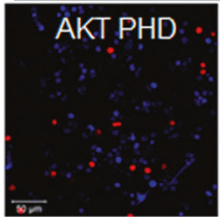

D

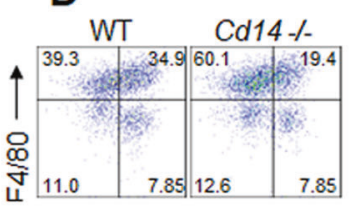

pHrodo thymocytes $\longrightarrow$

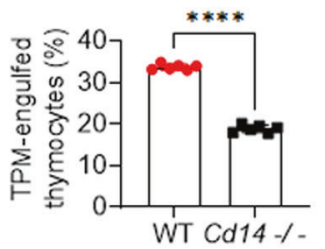

Camptothecin

Camptothecin

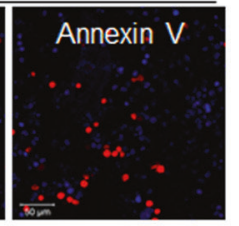

Anti-PI $(3,4,5) \mathrm{P}_{3}$

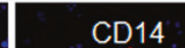

E
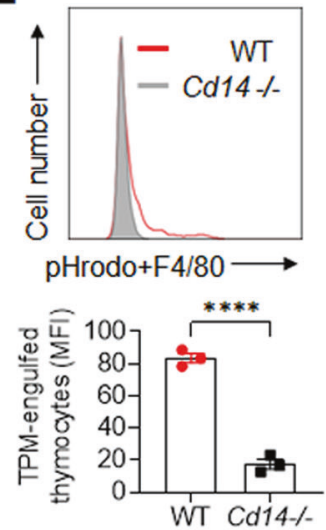

F

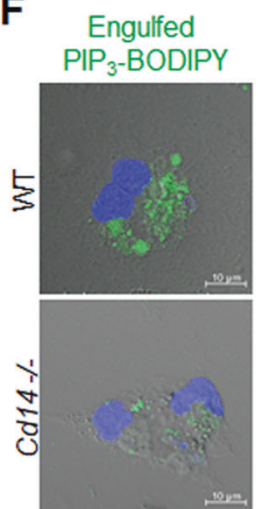

G

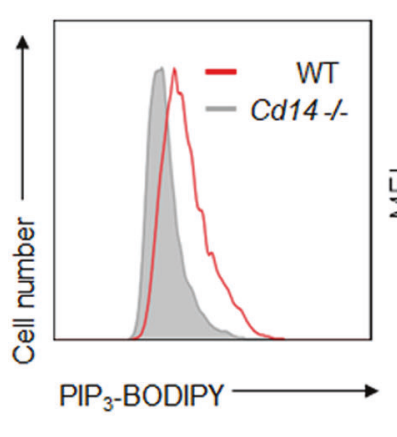

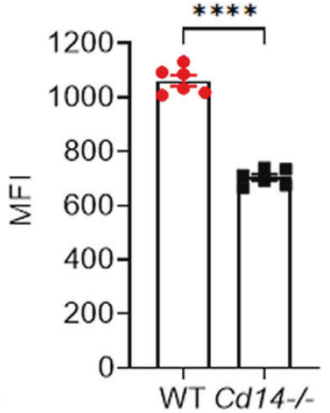

Fig. 3 PIP externalization and its role in phagocytosis. A Representative images of apoptotic cell detection by recombinant WT CD14 or mutant R4A CD14 protein. After inducing apoptosis with an anti-FAS antibody (100 ng/ml), HeLa cells incubated with recombinant WT or R4A CD14 were visualized using an anti-CD14 primary antibody and an FITC-labeled secondary antibody (scale bars, $10 \mu \mathrm{m})$. B Representative images of TPM phagocytosis of camptothecin-treated, pHrodo-labeled Jurkat cells using an antibody or recombinant proteins to mask externalized PS or PIPs. TPM phagocytosis of camptothecin-treated, pHrodo-labeled Jurkat cells was inhibited by an anti-PI(3,4,5)P $\mathrm{P}_{3}$ antibody, AKT PHD, Annexin V, and CD14 (scale bars, $50 \mu \mathrm{m}$ ). The red color represents engulfed apoptotic cells labeled with pHrodo dyes. C TPM phagocytosis of camptothecin-treated, pHrodo-labeled Jurkat cells was quantified in 8-10 low-power fields (mean \pm SD, $n=5-10$ ). D Representative flow cytometric plots (left) and percentages (right) of $\mathrm{F} 4 / 80^{+}$TPM phagocytosis of pHrodo-labeled thymocytes isolated from irradiated WT or $C d 14^{-l-}$ mice group ( $n=6$ per group). Thymocytes from irradiated mice were labeled with pHrodo for 30 min prior to adding TPMs from WT or $C d 14^{-/-}$mice for $1 \mathrm{hr}$ (mean \pm SD, $n=6$ ). E Representative flow cytometry plots (upper) and MFI values (lower) of in vivo phagocytosis of pHrodo-labeled apoptotic thymocytes by F4/80+ mouse peritoneal macrophages of WT or Cd14 ${ }^{-/-}$mice group $(n=3$ per group). Thymocytes from irradiated mice were labeled with pHrodo for $30 \mathrm{~min}$ prior to injecting the peritoneal cavity of WT or Cd14 ${ }^{-1-}$ mice for 15 min. F Representative fluorescent images (left) and intensities (right) of engulfed synthetic Bodipy-labeled PI(3,4,5) $\mathrm{P}_{3}$ in TPMs from WT or $\mathrm{Cd}_{14^{-/-}}$mice. Engulfed Bodipy-labeled $\mathrm{PIP}_{3}$ was visualized by confocal microscopy and quantified by fluorescence intensity using NIH ImageJ software (mean $\pm \mathrm{SD}, n=10$ ) after incubating the TPMs with $1 \mu \mathrm{g}$ of Bodipy-labeled $\mathrm{PI}(3,4,5) \mathrm{P}_{3}$ per well for 30 min (scale bars, $10 \mu \mathrm{m}$ ). G Representative flow cytometric plots (left) and MFI values (right) of engulfed synthetic Bodipy-labeled $\mathrm{PI}(3,4,5) \mathrm{P}_{3}$ in $\mathrm{Pl}^{-} / \mathrm{F} 4 / 80^{+} \mathrm{TPMs}$ from WT or $C d 14^{-1-}$ mice (mean \pm SD, $n=6$ ). All comparisons were performed by one-way ANOVA with Tukey's post-hoc multiple comparison test Fig. $3 \mathrm{~A}$ ) or unpaired student $t$ tests (Fig. 4D-F). All data are presented as the mean \pm SD for each group. ${ }^{*} p<0.05,{ }^{* *} p<0.01,{ }^{* * *} p<0.001$, **** $p<0.0001$ compared with camptothecin-treated controls. See also Supplementary Figs. 5-7. 
A

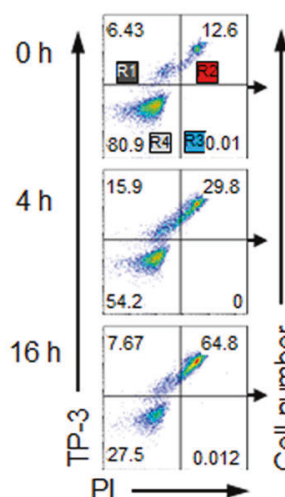

$\mathrm{Pl}$

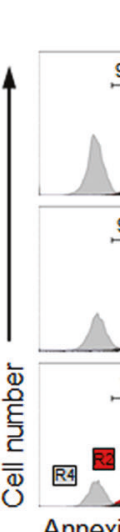

Jurkat cells (camptothecin)

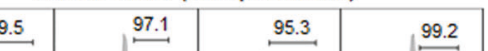

B

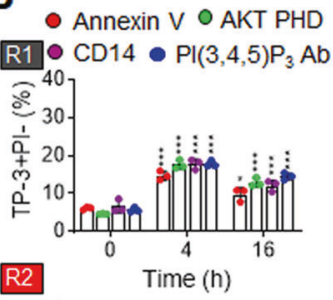

C

Jurkat cells (camptothecin, $16 \mathrm{~h}$ )
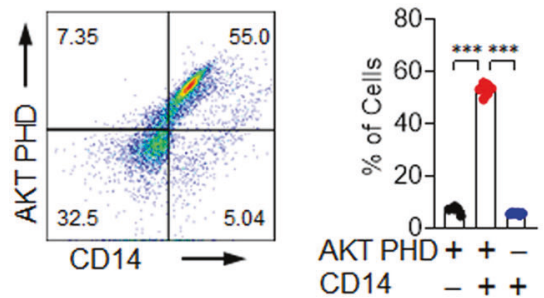

E

Jurkat cells (camptothecin, $16 \mathrm{~h}$ )
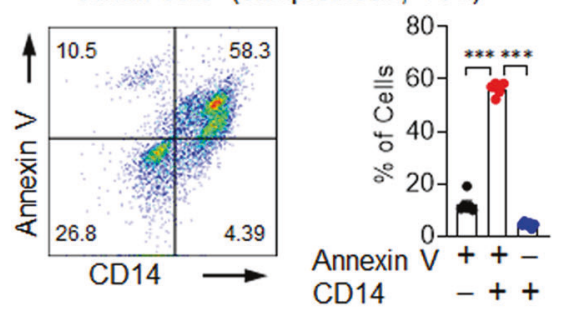

Jurkat cells (camptothecin, $16 \mathrm{~h}$ )
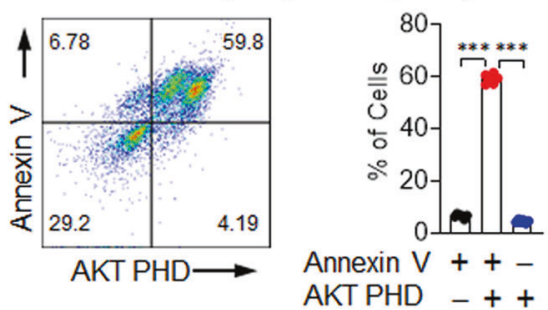

$\mathbf{F}$

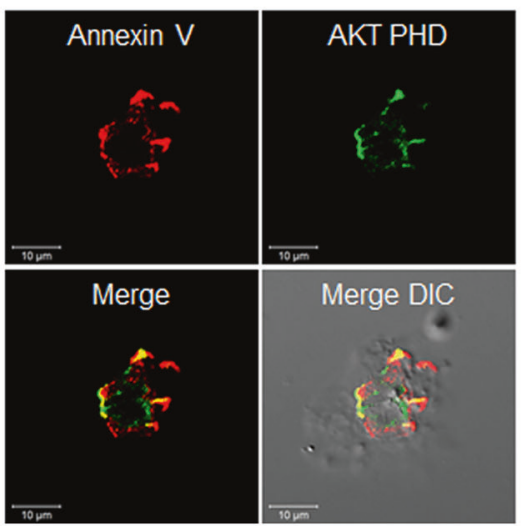

Fig. 4 In vitro induction of exofacial PIPs. A, B Flow cytometric analyses of Jurkat cells treated $0-16 \mathrm{~h}$ with $10 \mu \mathrm{M}$ camptothecin. A Representative flow cytometric plots (left) of TO-PRO-3 (TP-3) and propidium iodide (PI)-stained cells showing R1 (TP-3 $3^{+} \mathrm{PI}^{-}$), $\mathrm{R} 2\left(\mathrm{TP}-3^{+} \mathrm{PI}{ }^{+}\right.$), $\mathrm{R} 3$ $\left(\mathrm{TP}-3^{-} \mathrm{PI}^{+}\right.$), and R4 (TP-3 $3^{-} \mathrm{PI}^{-}$) subsets. Histograms (right) show the binding levels of Annexin V, AKT PHD, CD14, or PIP 3 antibody in R1 (dark gray), R2 (red), and R4 (light grey) subsets. B Percentage of Annexin V, AKT PHD, CD14, and PI(3,4,5) $P_{3}$ in R1 (upper low) and R2 (lower low) cells. C, D Flow cytometric analyses of Jurkat cells treated $16 \mathrm{~h}$ with $10 \mu \mathrm{M}$ camptothecin. C Representative flow cytometric plots (left) and binding percentages (right) of an AKT PHD and CD14 combination. D Representative flow cytometric plots (left) and binding percentages (right) of an Annexin V and AKT PHD combination. E Representative flow cytometric plots (left) and binding percentages (right) of an Annexin $\mathrm{V}$ and CD14 combination. F CHO cells treated $6 \mathrm{~h}$ with $10 \mu \mathrm{M}$ camptothecin and incubated with Annexin V and AKT PHD were detected with primary antibodies and Texas Red- or FITC-labeled secondary antibodies, respectively. See also Supplementary Fig. 8 and Supplementary Movie 2. All comparisons were performed by one-way ANOVA with Tukey's post-hoc multiple comparison test. All data are presented as the mean \pm SD for each group ( $n=6$ per group unless noted otherwise). ${ }^{*} p<0.05,{ }^{* *} p<0.01,{ }^{* * *} p<0.001$ compared to double-positive subsets.

mice than in WT mice (Supplementary Fig. 9A, B). Clearance mechanisms appeared to become saturated in $C d 14^{-1-}$ mice, but not in WT mice. Next, we asked if $\mathrm{PI}(3,4,5) \mathrm{P}_{3}$ was externalized on apoptotic cells of intestinal crypts. Casp ${ }^{+}$cells were stained using anti-PI $(3,4,5) \mathrm{P}_{3}$ antibody, and the results supported exofacial $\mathrm{PI}$ $(3,4,5) \mathrm{P}_{3}$ as a marker of apoptosis (Fig. 5E, Supplementary Fig. 9C).

As an alternative to irradiation, we asked whether PIP externalization accompanied treatment with caerulein, an exocrine secretagogue peptide that causes acute pancreatitis in rodents due to acinar cell apoptosis [47] and necroptosis [48]. Pancreas sections showed abundant Casp $^{+}$staining within the central exocrine acini after caerulein treatment (Fig. 5F, Supplementary Fig. 9D, E). Staining of $\mathrm{PI}(3,4,5) \mathrm{P}_{3}$ was readily apparent on the surfaces of the same cells. Therefore, in both of these in vivo settings, Casp $^{+}$cells were also positive for exofacial $\mathrm{PI}(3,4,5) \mathrm{P}_{3}$, consistent with both the in vitro results and with PIPs functioning as eat-me signals for the clearance of apoptotic cells by CD14expressing phagocytes. 
A

$\mathrm{Oh}$

$4 \mathrm{~h}$

$16 \mathrm{~h}$

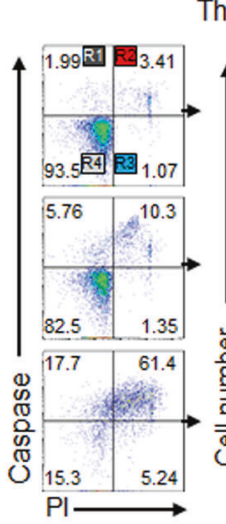

Thymocytes (Irradiation)

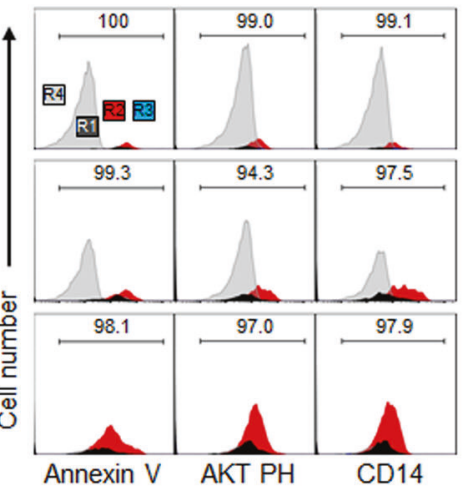

B

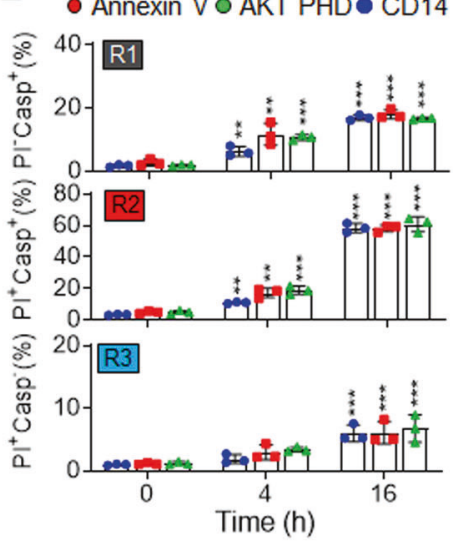

C

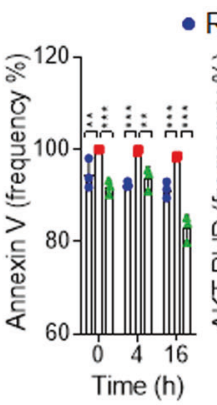

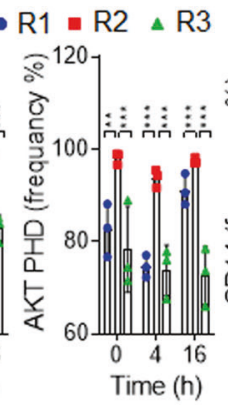

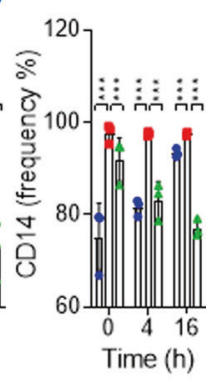

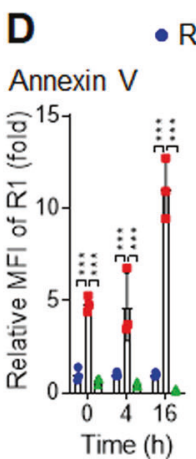

- $\mathrm{R} 1$ - R2 ^ R3

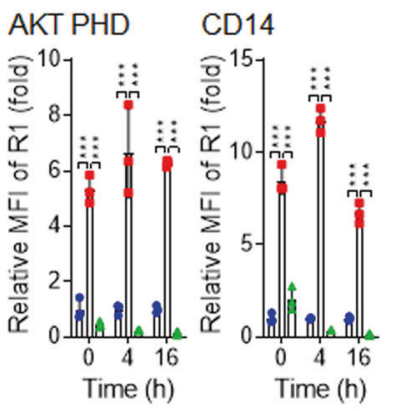

E

Time after Irradiation (16 h)

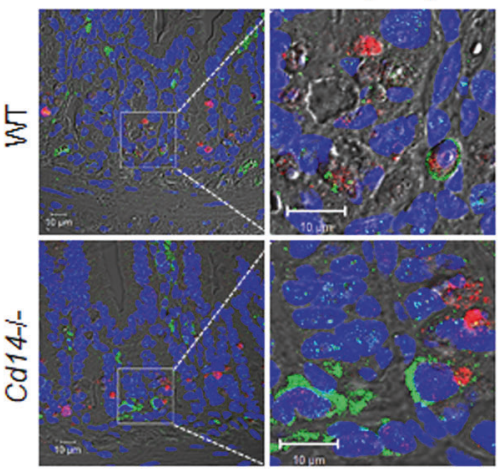

Cleaved caspase $3 / \mathrm{PI}(3,4,5) \mathrm{P}_{3} / \mathrm{DAPI}$
$\mathbf{F}$
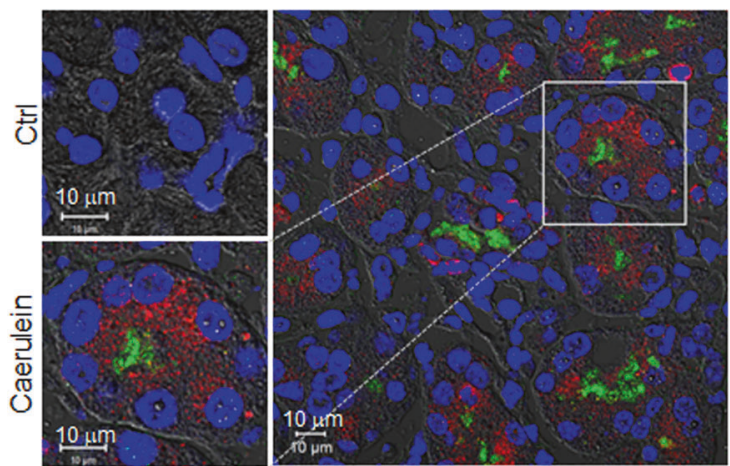

Cleaved caspase 3 / $\mathrm{PI}(3,4,5) \mathrm{P}_{3} / \mathrm{DAPI}$

Fig. 5 In vivo induction of exofacial PIPs. A-D Flow cytometric analyses of thymocytes from mice 0-16 h after irradiation (10 Gy). A Representative flow cytometric plots (left) of propidium iodide (PI) and cells stained for caspase 3/7 covalent suicide inhibitor (Casp) showing the R1 $\left(\mathrm{PI}^{-}\right.$Casp $\left.{ }^{+}\right), \mathrm{R} 2\left(\mathrm{PI}^{+}\right.$Casp $\left.{ }^{+}\right), \mathrm{R} 3\left(\mathrm{PI}^{+}\right.$Casp $\left.{ }^{-}\right)$, and $\mathrm{R} 4\left(\mathrm{PI}^{-}\right.$Casp $\left.{ }^{-}\right)$subsets. Histograms (right) show the binding levels of Annexin $\mathrm{V}$, AKT PHD, or CD14 in R1 (dark grey), R2 (red), R3 (light blue), and R4 (light grey) subsets $(n=3)$. B Percentages of Annexin V, AKT PHD and CD14 binding for R1 (upper row), R2 (middle row) and R3 (lower row) cells. C Frequencies of Annexin V, AKT PHD, and CD14 in R1, R2, and R3 thymocytes. D The relative MFI values in R1, R2, and R3 cells for AKT PHD, Annexin V, and CD14 binding. The MFI values were normalized to those of R1 at each time point. E Representative images of jejunum sections from irradiated WT and Cd14 ${ }^{-1-}$ mice were stained for cleaved caspase 3 (red), $\mathrm{PI}(3,4,5) \mathrm{P}_{3}$ (green), and DAPI (blue). F Representative images of pancreatic sections from mice treated with caerulein [47] stained with DAPI (blue), cleaved caspase 3 (red), and $\mathrm{PI}(3,4,5) \mathrm{P}_{3}$ (green). Scale bars, $10 \mu \mathrm{m}$. See also Supplementary Fig. 9. All comparisons were performed by one-way ANOVA with Tukey's post-hoc multiple comparison test. All data are presented as mean \pm SD for each group ( $n=3$ per group). ${ }^{*} p<0.05,{ }^{* *} p<0.01,{ }^{* * *} p<0.001$ compared to R1 subsets.

\section{DISCUSSION}

PIPs are mainly concentrated on the cytosolic surfaces of membranes [49]. Several PI kinases phosphorylate the 3, 4, and 5 hydroxyl positions of the inositol head group to yield seven distinct PIPs, each of which is uniquely distributed on cytosolic surfaces and subcellular organelles [14]. The PIPs dynamically participate in various distinct intracellular processes [16, 33], including lipid signaling, cell signaling, cytoskeletal reorganization, and membrane trafficking. Thus, PIPs orchestrate intracellular signaling effects to act as docking lipids to recruit cytosolic proteins or cytosolic domains of membrane proteins [14, 16, 33]. In contrast to the traditional roles of PIPs as pleiotropic regulators 
of intracellular signaling, the involvement of exofacial PIPs in apoptotic cell death and the physiological functions of exofacial PIPs have not been highlighted.

Using affinity-based proteomics, we identified that CD14 binding is required for the LPS-induced uptake of IC-IP 6 by both tissue-resident and peritoneal macrophages. We further showed that CD14 binds to structurally related PIPs, including $\mathrm{PI}(3,4,5) \mathrm{P}_{3}$. Given that apoptotic cells were previously shown to accumulate in mice lacking CD14 [21] and that CD14 mediates the uptake and metabolism of extracellular PIPs [22], we hypothesized that inwardly facing PIPs flip within the plasma membrane to expose their headgroups, similar to what is thought to occur for PS. Readily available and highly specific reagents for the identification of $\mathrm{PI}(3,4,5) \mathrm{P}_{3}, \mathrm{PI}(3,4) \mathrm{P}_{2}$, and $\mathrm{PI}(4,5) \mathrm{P}_{2}$ confirmed this hypothesis, including $\mathrm{PI}(3,4,5) \mathrm{P}_{3}$ and $\mathrm{PI}(4,5) \mathrm{P}_{2}$ antibodies and $\mathrm{PLC} \delta$ and AKT PHDs $[33,38]$. These reagents enabled clear visualization of small patches of exposed PIPs on some cells and larger membrane blebs on others, which was consistent with known apoptotic cell morphologies. The same reagents also showed that PIPs were exposed on apoptotic cell surfaces in vivo, especially after induction of apoptosis with irradiation or caerulein although a few intracellular PIPs can be exposed during tissue section process.

The reagents used to visualize externalized PIPs, including the antibody to $\mathrm{PI}(3,4,5) \mathrm{P}_{3}$ and AKT PHD also blocked phagocytosis of apoptotic Jurkat cells by peritoneal macrophages. These findings suggest that externalized PIPs are sufficient for phagocytic engulfment, although relative roles for PS, PIPs, and possibly other eat-me signals remain to be established. Recombinant CD14 blocked phagocyte engulfment, consistent with its role as an eatme signal receptor for endogenous exofacial PIPs. Specifically, we confirmed that $\mathrm{Cd}_{14}{ }^{-/-}$macrophages exhibited decreased uptake of synthetic Bodipy-labeled $\mathrm{PIP}_{3}$ compared to WT macrophages, suggesting that $\mathrm{CD} 14^{+}$macrophages are responsible for the recognition of externalized PIPs on apoptotic cell surfaces. These results are supported by the impaired ability of $\mathrm{Cd} 14^{-/-}$ macrophages to engulf apoptotic cells. Apoptotic cells have been shown to accumulate in $C d 14^{-1-}$ mice, but not in great numbers, consistent with the idea that additional mechanisms exist for apoptotic cell clearance [1, 3].

Of note, the apoptosis rates and the spatiotemporal distributions of putative eat-me signal(s) were virtually identical for the PIP-specific antibodies and AKT PHD, as well as for CD14 and Annexin V. These reagents clearly identified the same apoptotic cells, regardless of whether PS or PIPs were recognized. Undoubtedly, the cellular machinery for maintaining plasma membrane phospholipid asymmetry affects both PS and PIPs, and the breakdown of this energy-dependent process during apoptosis causes a loss of membrane polarity of both PS and PIPs. Consistent with this possibility, we found that, like PS, PIP exposure occurs after caspase activation and, therefore, late in the apoptotic process.

PS has been intensively studied as an eat-me signal [9]. By contrast, previous studies have neither identified PIPs as eat-me signals nor identified CD14 as a PIP receptor [21]. However, CD14 functions as a co-receptor along with TLR4 and MD-2 for the recognition and endocytosis of bacterial LPS, suggesting that CD14 may also interact with components of this pathway to recognize apoptotic cells. Consistently, $C d 14^{-1-}$ macrophages similarly failed to engulf apoptotic thymocytes. Additional experiments are required to determine whether TLR4 is involved in the clearance of apoptotic cells. Notably, reagents, such as anti$\mathrm{PI}(3,4,5) \mathrm{P}_{3}$ antibodies, AKT PHD, and recombinant CD14, which reduced the engulfment of apoptotic cells by TPM, did not block the engulfment of bacteria or latex beads. These reagents do not disrupt phagocytosis in general but instead are selective for PIP- mediated mechanisms. We conclude that apoptotic cells externalize PIP eat-me signals that are recognized and cleared by CD14 phagocytes.

\section{DATA AVAILABILITY}

The detailed procedures of Methods, five Figures, two Supplementary Movies, and nine Supplementary Figures are attached.

\section{REFERENCES}

1. Poon IK, Lucas CD, Rossi AG, Ravichandran KS. Apoptotic cell clearance: basic biology and therapeutic potential. Nat Rev Immunol. 2014;14:166-80.

2. Segawa K, Nagata S. An apoptotic 'Eat Me' signal: phosphatidylserine exposure. Trends Cell Biol. 2015;25:639-50.

3. Ravichandran KS, Lorenz U. Engulfment of apoptotic cells: signals for a good meal. Nat Rev Immunol. 2007;7:964-74.

4. Feng M, Jiang W, Kim BYS, Zhang CC, Fu Y-X, Weissman IL. Phagocytosis checkpoints as new targets for cancer immunotherapy. Nat Rev Cancer. 2019;19:568-86.

5. Hollville E, Martin SJ. Measuring apoptosis by microscopy and flow cytometry. Curr Protoc Immunol. 2016;112:14.38.11-24.

6. Fadok VA, Bratton DL, Frasch SC, Warner ML, Henson PM. The role of phosphatidylserine in recognition of apoptotic cells by phagocytes. Cell Death Differ. 1998;5:551-62.

7. Schlegel RA, Williamson P. Phosphatidylserine, a death knell. Cell Death Differ. 2001;8:551-63.

8. Birge RB, Boeltz S, Kumar S, Carlson J, Wanderley J, Calianese D, et al. Phosphatidylserine is a global immunosuppressive signal in efferocytosis, infectious disease, and cancer. Cell Death Differ. 2016;23:962-78.

9. Arandjelovic S, Ravichandran KS. Phagocytosis of apoptotic cells in homeostasis. Nat Immunol. 2015;16:907-17.

10. Drin G. Topological regulation of lipid balance in cells. Annu Rev Biochem. 2014;83:51-77.

11. Fadeel B, Xue D. The ins and outs of phospholipid asymmetry in the plasma membrane: roles in health and disease. Crit Rev Biochem Mol Biol. 2009;44:264-77.

12. Segawa K, Kurata S, Yanagihashi Y, Brummelkamp TR, Matsuda F, Nagata S. Caspase-mediated cleavage of phospholipid flippase for apoptotic phosphatidylserine exposure. Science. 2014;344:1164-8.

13. van Meer G, Voelker DR, Feigenson GW. Membrane lipids: where they are and how they behave. Nat Rev Mol Cell Biol. 2008:9:112-24.

14. Balla T. Phosphoinositides: tiny lipids with giant impact on cell regulation. Physiol Rev. 2013;93:1019-137.

15. Cantley LC. The phosphoinositide 3-kinase pathway. Science. 2002;296:1655-7.

16. Di Paolo G, De Camilli P. Phosphoinositides in cell regulation and membrane dynamics. Nature. 2006;443:651-7.

17. Brubaker SW, Bonham KS, Zanoni I, Kagan JC. Innate immune pattern recognition: a cell biological perspective. Annu Rev Immunol. 2015;33:257-90.

18. Zanoni I, Ostuni R, Capuano G, Collini M, Caccia M, Ronchi AE, et al. CD14 regulates the dendritic cell life cycle after LPS exposure through NFAT activation. Nature. 2009;460:264-8

19. Tan Y, Zanoni I, Cullen Thomas W, Goodman Andrew L, Kagan, Jonathan C. Mechanisms of Toll-like receptor 4 endocytosis reveal a common immuneevasion strategy used by pathogenic and commensal bacteria. Immunity. 2015;43:909-22.

20. Rajaiah R, Perkins DJ, Ireland DDC, Vogel SN. CD14 dependence of TLR4 endocytosis and TRIF signaling displays ligand specificity and is dissociable in endotoxin tolerance. Proc Natl Acad Sci. 2015;112:8391-6.

21. Gregory CD. CD14-dependent clearance of apoptotic cells: relevance to the immune system. Curr Opin Immunol. 2000;12:27-34.

22. Wang PY, Munford RS. CD14-dependent internalization and metabolism of extracellular phosphatidylinositol by monocytes. J Biol Chem. 1999;274:23235-41.

23. Devitt A, Moffatt OD, Raykundalia C, Capra JD, Simmons DL, Gregory CD. Human CD14 mediates recognition and phagocytosis of apoptotic cells. Nature. 1998;392:505-9.

24. Devitt A, Parker KG, Ogden CA, Oldreive C, Clay MF, Melville LA, et al. Persistence of apoptotic cells without autoimmune disease or inflammation in CD14-/mice. J Cell Biol. 2004;167:1161-70.

25. Kim OH, Kim H, Kang J, Yang D, Kang YH, Lee DH, et al. Impaired phagocytosis of apoptotic cells causes accumulation of bone marrow-derived macrophages in aged mice. BMB Rep. 2017;50:43-8.

26. Lee J-H, Phelan P, Shin M, Oh B-C, Han X, Im S-S, et al. SREBP-1a-stimulated lipid synthesis is required for macrophage phagocytosis downstream of TLR4-directed mTORC1. Proc Natl Acad Sci. 2018;115:E12228-34. 
27. Auger KR, Serunian LA, Soltoff SP, Libby P, Cantley LC. PDGF-dependent tyrosine phosphorylation stimulates production of novel polyphosphoinositides in intact cells. Cell. 1989;57:167-75.

28. Hopkins BD, Goncalves MD, Cantley LC. Insulin-PI3K signalling: an evolutionarily insulated metabolic driver of cancer. Nat Rev Endocrinol. 2020;16:276-83.

29. Baek JO, Roh JY, Jung Y. Oral tolerance inhibits atopic dermatitis-like type 2 inflammation in mice by modulating immune microenvironments. Allergy. 2017;72:397-406.

30. Kim OH, Booth CJ, Choi HS, Lee J, Kang J, Hur J, et al. High-phytate/low-calcium diet is a risk factor for crystal nephropathies, renal phosphate wasting, and bone loss. eLife. 2020;9:e52709.

31. Desai AG, Thakur ML. Radiopharmaceuticals for spleen and bone marrow studies. Semin Nucl Med. 1985;15:229-38.

32. Wang PY, Kitchens RL, Munford RS. Phosphatidylinositides bind to plasma membrane CD14 and can prevent monocyte activation by bacterial lipopolysaccharide. J Biol Chem. 1998;273:24309-13.

33. Lemmon MA. Membrane recognition by phospholipid-binding domains. Nat Rev Mol Cell Biol. 2008;9:99-111.

34. Kang JK, Kim OH, Hur J, Yu SH, Lamichhane S, Lee JW, et al. Increased intracellular Ca $(2+)$ concentrations prevent membrane localization of $\mathrm{PH}$ domains through the formation of $\mathrm{Ca}(2+)$-phosphoinositides. Proc Natl Acad Sci USA. 2017;114:11926-31.

35. Kim Jl, Lee CJ, Jin MS, Lee CH, Paik SG, Lee H, et al. Crystal structure of CD14 and its implications for lipopolysaccharide signaling. J Biol Chem. 2005;280:11347-51.

36. Fadok VA, Voelker DR, Campbell PA, Cohen JJ, Bratton DL, Henson PM. Exposure of phosphatidylserine on the surface of apoptotic lymphocytes triggers specific recognition and removal by macrophages. J Immunol. 1992;148:2207-16.

37. Devitt A, Pierce S, Oldreive C, Shingler WH, Gregory CD. CD14-dependent clearance of apoptotic cells by human macrophages: the role of phosphatidylserine. Cell Death Differ. 2003;10:371-82.

38. Ceccato L, Chicanne G, Nahoum V, Pons V, Payrastre B, Gaits-lacovoni F, et al. PLIF: a rapid, accurate method to detect and quantitatively assess protein-lipid interactions. Sci Signal. 2016;9:rs2.

39. Werner ED, Lee J, Hansen L, Yuan M, Shoelson SE. Insulin resistance due to phosphorylation of insulin receptor substrate-1 at serine 302. J Biol Chem. 2004;279:35298-305.

40. Dixon SJ, Lemberg KM, Lamprecht MR, Skouta R, Zaitsev EM, Gleason CE, et al. Ferroptosis: an iron-dependent form of nonapoptotic cell death. Cell. 2012;149:1060-72.

41. Yang WS, SriRamaratnam R, Welsch ME, Shimada K, Skouta R, Viswanathan VS, et al. Regulation of ferroptotic cancer cell death by GPX4. Cell. 2014;156:317-31.

42. Zhou J, Li G, Han G, Feng S, Liu Y, Chen J, et al. Emodin induced necroptosis in the glioma cell line U251 via the TNF-a/RIP1/RIP3 pathway. Investigational N. Drugs. 2020;38:50-9.

43. Hafner-Bratkovič I, Sušjan P, Lainšček D, Tapia-Abellán A, Cerović K, Kadunc L, et al. NLRP3 lacking the leucine-rich repeat domain can be fully activated via the canonical inflammasome pathway. Nat Commun. 2018;9:5182.

44. Andree HA, Reutelingsperger CP, Hauptmann R, Hemker HC, Hermens WT, Willems GM. Binding of vascular anticoagulant alpha (VAC alpha) to planar phospholipid bilayers. J Biol Chem. 1990;265:4923-8.

45. Tait JF, Gibson D, Fujikawa K. Phospholipid binding properties of human placental anticoagulant protein-I, a member of the lipocortin family. J Biol Chem. 1989;264:7944-9.

46. Jiang L, Tixeira R, Caruso S, Atkin-Smith GK, Baxter AA, Paone S, et al. Monitoring the progression of cell death and the disassembly of dying cells by flow cytometry. Nat Protoc. 2016;11:655-63.

47. Jensen JN, Cameron E, Garay MV, Starkey TW, Gianani R, Jensen J. Recapitulation of elements of embryonic development in adult mouse pancreatic regeneration. Gastroenterology. 2005;128:728-41.

48. Boonchan M, Arimochi $\mathrm{H}$, Otsuka K, Kobayashi T, Uehara $\mathrm{H}$, Jaroonwitchawan $\mathrm{T}$, et al. Necroptosis protects against exacerbation of acute pancreatitis. Cell Death Dis. 2021;12:601.

49. Schink KO, Tan KW, Stenmark H. Phosphoinositides in control of membrane dynamics. Annu Rev Cell Developmental Biol. 2016;32:143-71.

50. Macbeth MR, Schubert HL, Vandemark AP, Lingam AT, Hill CP, Bass BL. Inositol hexakisphosphate is bound in the ADAR2 core and required for RNA editing. Science. 2005;309:1534-9.

\section{ACKNOWLEDGEMENTS}

We thank Drs. Amy Wagers (Joslin Diabetes Center and Harvard University), Young Jae Lee (Gachon University), and Seung-Soon Im (Keimyung University) for helpful discussions.

\section{AUTHOR CONTRIBUTIONS}

All authors contributed equally in edition and proofreading of the manuscript. OHK, SES, and BCO designed the studies. OHK, GHK, JH, JL, YJ, IH, HL, SYS, DHL, CSL, IL, JL, $\mathrm{YP}, \mathrm{HK}$, and BCO performed the experiments and analyzed the data and statistical analysis. SBW provided the pancreatic section and analyzed the data. OHK, SES, and $\mathrm{BCO}$ wrote the manuscript.

\section{FUNDING}

This study was supported by grants from the Korea Ministry of Health \& Welfare (HI14C1135; BCO), the Basic Science Research Program (2017R1D1A1B03031094; OHK), the Mid-career Researcher Program (2019R1A2C2008130; BCO), the Medical Research Center (No. NRF-2021R1A5A2030333) of the National Research Foundation (NRF) funded by the Korea government and NIH grants R01 DK095327 (SES), R01 DK108936 (SES), R01 HL133329 (SES), and P30 DK036836 (Joslin Diabetes Center).

\section{COMPETING INTERESTS}

The authors declare no competing interests.

\section{ETHICS APPROVAL}

All animal experiment protocols approved by the Animal Ethics Committee of Gachon University, Lee Gil Ya Cancer and Diabetes Institute (LCDI20130062, LCDI20160030, and LCDI20210035) and were in compliance with ethical regulations and institutional guidelines.

\section{ADDITIONAL INFORMATION}

Supplementary information The online version contains supplementary material available at https://doi.org/10.1038/s41418-022-00931-2.

Correspondence and requests for materials should be addressed to Steven E. Shoelson or Byung-Chul Oh.

Reprints and permission information is available at http://www.nature.com/ reprints

Publisher's note Springer Nature remains neutral with regard to jurisdictional claims in published maps and institutional affiliations.

(i) Open Access This article is licensed under a Creative Commons Attribution 4.0 International License, which permits use, sharing, adaptation, distribution and reproduction in any medium or format, as long as you give appropriate credit to the original author(s) and the source, provide a link to the Creative Commons license, and indicate if changes were made. The images or other third party material in this article are included in the article's Creative Commons license, unless indicated otherwise in a credit line to the material. If material is not included in the article's Creative Commons license and your intended use is not permitted by statutory regulation or exceeds the permitted use, you will need to obtain permission directly from the copyright holder. To view a copy of this license, visit http://creativecommons. org/licenses/by/4.0/.

(c) The Author(s) 2022 